\title{
Threatened fishes of the world: Liobagrus kingi Tchang 1935 (Actinopterygii: Amblycipitidae)
}

\author{
Bo Yang $\cdot$ Xiao-Yong Chen $\cdot$ Jun-Xing Yang
}

Received: 19 September 2007 / Accepted: 26 March 2008 / Published online: 20 May 2008

(C) Springer Science + Business Media B.V. 2008

Common name: Yang-si (Chinese). King's bullhead (English). Conservation status: Endangered-China Red Data Book of Endangered Animal, Pisces (Yue and Chen 1998). Identification: Body elongate and compressed, head broad and depressed, snout blunt, rounded and depressed, eyes small and nearer to tip of snout, mouth large, terminal and nearly transverse, lower jaw slightly projecting, barbels four pairs, posterior barbels shorter than head length, dorsal and pectoral spine both with serrations, body naked and without lateral line (Chu and Kuang 1990; He 1999). Body color in alcohol grayish, with small dark spots, fins yellowish (Tchang 1935). Dorsal i+6, Anal iii+ 10-13, Pectoral i+7, Pelvic i+5. Maximum size 95.0 mm SL (He 1999). Distribution: Endemic to China and distributed only in Dianchi Lake and its tributaries, Yunnan Province. Abundance: It had been a familiar sight in Dianchi Lake, though the number was not great (Yue and Chen 1998). Two specimens were collected in 1960, Haigeng, Kunming (Cat. No.: KIZ1960000611, KIZ1960000612), and after that no specimens were collected (Chu and Kuang 1990). Habitat and ecology: Carnivorous, lives rapidly flowing streams with plenty of rocks at the water bottom (Yue and Chen 1998). According to collected location of above two speci-

B. Yang $\cdot$ X.-Y. Chen $(\bowtie) \cdot$ J.-X. Yang $(\bowtie)$

Department of Systematic Zoology, Kunming Institute of Zoology, Chinese Academy of Sciences,

Kunming, Yunnan 650223, People's Republic of China e-mail: chenxy@mail.kiz.ac.cn e-mail: yangjx@mail.kiz.ac.cn

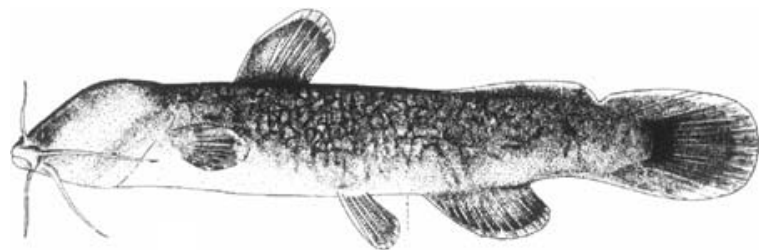

mens, it also lived in Dianchi Lake itself. Reproduction: Nothing is known about its reproduction. Threats: Habitat degradation and loss are the critical threat, including the overdischarge of domestic and industrial wastewater which seriously polluted the water, and the construction of water conservation projects like reservoirs, hydropower stations, which may result in rivulets drying up, and the habitat is lost. Conservation recommendations: Liobagrus kingi should be listed as a state protected animal. The conservation status of $L$. kingi can be improved through effective habitat protection and public awareness programs.

\section{References}

Chu X, Kuang P (1990) Amblycipitidae. In: Chu X-L, Chen Y-R (eds) The fishes of Yunnan, China. Part II. Science, Beijing, China, p. 166-169, 313 p

He M (1999) Amblycipitidae. In: Chu X-L, Cheng B-S, Dai D-Y (eds) Faunica Sinica. Osteichthyes. Siluriformes. Science, Beijing, China, pp 103-110 i-vii + 1-230

Tchang T (1935) A new catfish from Yunnan. Bull Fan Meml Inst Biol 6(4):95-97

Yue P, Chen Y (eds) (1998) China Red Data Book of Endangered Animals, Pisces. Science, Beijing, China, p 247 